\title{
THORAX
}

Editorial

\section{Viral infections: a role in the lung disease of cystic fibrosis?}

From early in life the lungs of patients with cystic fibrosis are subject to recurrent episodes of bacterial infection. Initially infection is with Staphylococcus aureus, which may become chronic, though some episodes of respiratory exacerbation are due to Haemophilus influenzae. ${ }^{1}$ Later Pseudomonas aeruginosa becomes the predominant organism in sputum and largely determines morbidity and mortality, presenting the major management problem for physicians caring for adult patients with cystic fibrosis. ${ }^{23}$

The reasons for this sequence of infection with the generation of a vicious circle of injury and infection is not clear, and there remain important unanswered questions. Is bacterial infection linked to the defect in chloride transport? How is bacterial infection of the airways initiated? What factors predispose to colonisation with $P$ aeruginosa, an organism of only modest virulence in healthy airways? It has been suggested that the answer to the latter two questions is an independent insult to the airways, such as viral infection, rather than intrinsic properties either of the bacteria or of the ion transport defect. For $P$ aeruginosa colonisation other factors enhance retention specifically of this organism in the lungs, such as the host defence mediated lung injury and bacterial virulence factors. ${ }^{23}$ There appears to be little spread from patient to patient and most infection is likely to occur directly from the environment. These factors may all be important in the maintenance of chronic infection but possibly not in its initiation.

It has been suggested that viral infection is of considerable importance; but in established lung disease this is difficult to determine, and studies in young children with cystic fibrosis are not easy to carry out in terms of defining injury to the airways. There is evidence that infection with respiratory syncytial virus is sometimes a factor in the acquisition of $P$ aeruginosa. ${ }^{45}$ In this issue of Thorax Dr HK Johansen and Professor N Høiby provide further evidence that viral infection may be a factor in the acquisition of $P$ aeruginosa and in the onset of chronic infection. ${ }^{6}$

In a review of 300 patients at the Danish Cystic Fibrosis Centre they recorded the dates of the first isolation of $P$ aeruginosa and of the start of chronic infection, defined as continuous culture of the bacterium from the sputum for six months and IgG antibody response. The Danish centre is in a unique position to do this, having documented the histories of the patients over many years. Patients seen during 1965-90 were included in this study. Two thirds of the patients first had $P$ aeruginosa isolated from their sputum during October-March. In addition, nearly $70 \%$ of the patients studied started to have chronic infection during these months. In most patients these two events were separate, the sputum being clear of $P$ aeruginosa for a time. The authors concluded from this clear relation to the winter months over 25 years, during which many changes in management occurred, that there may be some seasonal factor in the acquisition and maintenance of $P$ aeruginosa infection in cystic fibrosis. Unfortunately, the study was retrospective and viral investigations were not available.
The months October to March, however, are the peak time for viral infection in Denmark and evidence from other sources supports this. It would be interesting to know whether $P$ aeruginosa is acquired during April-September in the southern hemisphere. Exacerbations of respiratory symptoms in cystic fibrosis have been reported to be associated with viral infection in $17-39 \%$ of episodes. ${ }^{78}$ Conway et $a l^{9}$ report in this issue the acutely deleterious effects of influenza A virus infection in older patients with chronic $P$ aeruginosa infection. They suggest that such patients should be offered immunisation against influenza each autumn to avoid serious respiratory deterioration. The timing of viral infection has also been shown to be associated with the timing of deterioration in lung function in cystic fibrosis, again suggesting an important causal link between viral and bacterial infection. There is no evidence, however, that viral infections are more common in patients with cystic fibrosis-rather such infections appear to have more impact in these patients with pre-existing abnormalities of the respiratory tract.

The implications of the study of Johansen and Høiby are that greater account should be taken of the role of virus infection, both in children and in adults. Hence there is a testable hypothesis-namely, that viral infection of the airways early in life in patients with cystic fibrosis initiates changes allowing bacterial infection to become established and that later viral infections have a permissive effect on the acquisition of $P$ aeruginosa infection and of chronic colonisation of the airways with this organism. With firmer evidence of the role of viral infection as an initiating and facilitating factor in lung disease in cystic fibrosis we may have an opportunity to devise treatment strategies that would protect and preserve lung function in the infant, leading to better long term survival.

D J SHALE

David Davies Professor of Respiratory and Communicable Diseases,

University of Wales College of Medicine,

Llandough Hospital, Penarth.

South Glamorgan CF6 IXX

Reprint requests to Professor Shale.

1 Rayner RJ, Hiller EJ, Ispahani P, Baker M. Haemophilus infection in cystic fibrosis. Arch Dis Child 1990;65:225-8.

2 Høiby N, Koch C. Pseudomonas aeruginosa infection in cystic fibrosis and its management. Thorax 1990;45:881-4.

3 Elborn JS, Shale DJ. Lung injury in cystic fibrosis. Thorax 1990;45:970-3.

4 Petersen NT, Høiby N, Mordhorst CH, Lind K, Flensborg EW, Bruun B. Respiratory infections in cystic fibrosis patients caused by virus, chlamydia and mycoplasma - possible synergism with Pseudomonas aeruginosa. Acta Paediatr Scand 1981;70:623-8.

5 Abman SH, Ogle LW, Butler Simon N, Rumack CM, Accurso FJ. Role of respiratory syncitial virus in early hospitalisation for respiratory distress in young infants with cystic fibrosis. J Pediatr 1988;113:826-30.

6 Johansen HK, Høiby N. Seasonal onset of initial colonisation and chronic Pseudomonas aeruginosa infection in patients with cystic fibrosis in Denmark. Thorax 1992;47:109-11.

7 Efthimiou J, Hodson ME, Taylor P, Taylor AG, Batten JC. Important of viruses and Legionella pneumophila in respiratory exacerbations of young adults with cystic fibrosis. Thorax 1984;39:150-4.

8 Wang EEL, Prober CG, Manson B, Corey M, Levison H. Association of respiratory viral infections with pulmonary deterioration in patients with respiratory viral infections with pulmonary deteric

9 Conway SP, Simmonds EJ, Littlewood JM. Acute severe deterioration in cystic fibrosis associated with Influenza $A$ virus infection. Thorax 1992;47:112-4: 